\title{
EL ESCRITOR PARAGUAYO Y LA TRADICIÓN. DISPUTAS EN LA POST-DICTADURA
}

The Paraguayan writer and tradition. Debates in Paraguay post-dictatorship

\author{
CARla DANIEla BENISZ
}

UNIVERSIDAD AUTÓNOMA DE ENTRE RÍOS (UADER) (ARGENTINA) carlabenisz@hotmail.com

\section{RECIBIDO: 27 DE MARZO DE $2018 \quad$ ACEPTADO: 3 DE MAYO DE 2018}

RESUMEN: El artículo presenta un episodio poco estudiado por la crítica literaria latinoamericana: la polémica entre los escritores paraguayos Augusto Roa Bastos y Carlos Villagra Marsal en 1989. La pertinencia de su estudio radica en que la polémica permite abordar tanto aspectos de la literatura paraguaya contemporánea como de los debates intelectuales del campo intelectual paraguayo después de caída la dictadura de Alfredo Stroessner (1954-1989). Si bien la polémica despertó cuestiones éticas y personales que, finalmente, dominaron sus interpretaciones posteriores, aquí trataré de presentarla, así sea sucintamente, desde los tres aspectos que esta polémica implica: el literario, el ético y el histórico. En primer lugar, el planteo literario se refiere a la constitución de la literatura paraguaya como literatura nacional. En segundo lugar, la cuestión ética abarca el modo en que los escritores se posicionaron ante el exilio, la dictadura y la transición. Finalmente, se considerará aquí la polémica como síntoma de la coyuntura histórica. En consecuencia, el género de la polémica resulta un tipo de discurso que posibilita la generación de conocimiento y no solo la anulación de la dialéctica.

PALABRAS ClaVE: Polémica, Paraguay, exilio, literatura, campo intelectual.

ABSTRACT: This article analyses the polemic between two Paraguayan writers, Augusto Roa Bastos and Carlos Villagra Marsal, in the year of 1989. This episode was not enough studied by Latin-American critics but it allows us to describe structural aspects of Paraguayan Literature and the debates in the intellectual field after the dictatorship of Alfredo Stroessner (1954-1989). Even though the polemic awoke ethical and personal questions, which lately dominated its interpretations, this article will analyse it since three aspects: literary, ethical and historical. Firstly, the literary aspect is about how Paraguayan Literature may become a national literature. Secondly, the ethical aspect involves how writers positioned themselves with regard to exile, dictatorship and transition. Finally, this article will analyse the polemic as symptom of the historic juncture. In consequence, polemic as genre is considered as a type of discourse which allows the development of critical knowledge and not only means the denegation of dialectics.

KEYWORDS: Polemic, Paraguay, exile, literature, intellectual field. 


\section{UN GÉNERO EN DISPUTA}

El discurso polémico en el ámbito de la literatura latinoamericana es tan extenso como ella misma. En el siglo XIX, los debates acerca de los diversos proyectos políticos aplicables a las naciones latinoamericanas en ciernes, legaron un importante corpus de obras ficcionales y ensayos. Ya en el 900, el proceso de modernización y sus consecuencias en la función intelectual, en pos de su profesionalización, también trajeron aparejados quiebres y sacudidas en el campo intelectual del Modernismo. Se puede afirmar que los grandes hitos de la literatura latinoamericana (las vanguardias, el boom, por ejemplo) supuraron en polémicas las tensiones entre las tendencias ya asentadas en el campo y los nuevos mecanismos de legitimación. ${ }^{1}$ En el contexto de las postdictaduras de la década de 1980, las polémicas expresan e intervienen en la reconfiguración del campo intelectual. Lo que expresan, además, como formas mediadoras del campo, es justamente la elaboración de un nuevo contrato social y la instalación del régimen democrático como doxa, con la cual se sella la ilegitimidad de cualquier propaganda por un retorno al autoritarismo, así como a los proyectos setentistas alternativos a la democracia burguesa. Como intentaré desarrollar en este artículo, a partir de un caso puntual, el caso paraguayo, este tumultuoso contexto de cambios favoreció el despertar polémico ya que aseguraba, por un lado, la apertura democrática que toda expresión de disenso requiere y, por otro, porque el mismo ejercicio de la polémica posibilitó un espacio de "gestión del conflicto" (cf. Amossy 2014) en el que el conflicto es asumido como algo que puede ser absorbido socialmente, es decir, que puede ser regulado por un contrato social en vías de solidificación. Quizás por todo esto se trate del último gran episodio polémico en la literatura latinoamericana. ${ }^{2}$

Sin embargo, esta "apología de la polémica", según la caracterización de Ruth Amossy (2014), en tanto discurso portador de una función social, no es la propiedad que suele caracterizar al género en los abordajes tradicionales. Una impugnación célebre al discurso polémico es la que realizara Michel Foucault en una entrevista a Paul Rabinow (1984). Entonces Foucault afirmó que la polémica oblitera cualquier posibilidad de que, a partir del intercambio dialógico, se alcance verdad alguna, ya que pone en riesgo "la moral de la búsqueda de la verdad y de la relación con el otro” (Rabinow 1984: 381);3 el polemista establece una relación desigual y beligerante con su interlocutor, a quien no considera un par, sino un adversario que debe anular. Para Foucault, de este modo, la toma de la palabra polémica necesariamente parte de la anulación del otro, reducido a receptor pasivo y víctima del proceso.

Esta ética del diálogo igualitario puede sonar contradictoria con episodios polémicos de la misma trayectoria intelectual de Foucault e incluso con ciertos aspectos de su obra, más interesada en los quiebres y fugas que en las continuidades; algo de ello está en la respuesta que le dedica Jonathan Crewe (2004) a este reportaje de Foucault. Crewe asocia la polémica con la violencia y la beligerancia, por lo cual el rechazo hacia ella, que encuentra no solo en Foucault sino en la academia estadounidense de las últimas décadas, se relaciona con el rechazo a la violencia, etimológicamente presente en el género a través de su raíz, polemos. A partir de ello,

\footnotetext{
1 Al respecto, Marcela Croce (2006 y 2007) presenta una compilación de estas polémicas.

2 Michel Murat (2003: 14) caracteriza el periodo actual como una suerte de "depresión post-panfletaria".

${ }^{3}$ La traducción de la cita, así como la de toda la bibliografía en idioma no castellano, me pertenece.
} 
Crewe se pregunta, de modo retórico, si una historia intelectual legítima sería una historia de la no violencia (2004: 138). Negar tajantemente la violencia como elemento de cultura, negaría -casi- la historia intelectual.

Es significativo, por otro lado, el aporte de Ruth Amossy ya mencionado, porque entiende la polémica como elemento funcional de una sociedad democrática. De modo que "la polémica ocupa funciones sociales importantes precisamente en razón de aquello que generalmente se le reprocha: una gestión verbal del conflicto efectuado sobre el modo del disentimiento" (Amossy 2014: 12). La autora aclara que la polémica tiende a la dicotomización y a la polarización; de modo que este canal social y discursivo del conflicto sirve más para sentar las diferencias que para resolverlas. La polarización puede, también, reconfigurar los grupos en relación con las posiciones en polémica (Amossy 2014: 60), es decir, puede contribuir a la reestructuración del campo intelectual.

Desde esta perspectiva se puede entender el fenómeno que se dio en el campo intelectual latinoamericano post-dictaduras respecto del estallido de distintas polémicas intelectuales a la par que se asentaba el proceso de democratización. ${ }^{4}$ A pesar del "ajuste de cuentas" que estas polémicas pudieron significar entre los escritores que asumían el proceso histórico desde perspectivas contrapuestas, las controversias fueron también síntoma de un campo intelectual que recobraba dinamismo. Como toda lucha dentro del campo, los escritores e intelectuales funcionan a modo de fuerzas que -en su misma confrontación- dinamizan y dan cuerpo al campo. En palabras de Pierre Bourdieu, estos conflictos "que dividen el campo intelectual de acuerdo con sus líneas de fuerza", "constituyen sin duda alguna el factor más decisivo del cambio cultural” (2002 [1966]: 41).

Este fenómeno fue particularmente rico en una literatura que cuenta con pocos estudios críticos, la literatura paraguaya, y lo fue de modo casi proporcional a lo que significó la apertura democrática después de la larga dictadura de Alfredo Stroessner (1954-1989). Este historial polémico enfrentó a determinadas figuras de escritores, tras las cuales se enfrentaban, a su vez, distintos sectores del campo intelectual y planteó temas que, durante la dictadura, o bien no habían encontrado eco en el laberinto de la censura, o bien ni siquiera habían sido planteados.

\section{POST-DICTADURA Y QUIEBRE DEL FRENTE INTELECTUAL}

El 3 de febrero de 1989 el general Andrés Rodríguez derroca a Stroessner, asume el gobierno paraguayo e inicia con un golpe militar, paradójicamente, el proceso de transición a la democracia en Paraguay. Rodríguez refrendaría su mandato en elecciones, hasta que en 1992 se sanciona la nueva Constitución y, en 1993, se eligen democráticamente Presidente y autoridades por primera vez en la historia paraguaya. La caída de Stroessner significa, en términos generales, un replanteo de las posibilidades mismas de la democracia y de la revisión de concepciones

\footnotetext{
4 Para el caso argentino, puede verse la tesis doctoral de José Luis de Diego (2000); algunos apuntes sobre lo acontecido en Chile en Richard (2007), y una comparación entre dos polémicas célebres en Argentina y Paraguay en Benisz (2017).
} 
anquilosadas en el imaginario social, lo cual llevó a Benjamín Arditi (1989) a postular, con el poststronismo, el fin del "mito paralizador" en que se encontraba inmersa la sociedad paraguaya. ${ }^{5}$

De todos modos, ya en los años ochenta, se vislumbran algunas transformaciones: por primera vez no se prorroga el estado de sitio, se permite el regreso de algunos exiliados y la realización de manifestaciones obreras y estudiantiles. Aunque aún sobrevendrían importantes episodios represivos: en 1982 acontece la expulsión oficial de Augusto Roa Bastos 6 y son clausurados Radio Nanduti y el diario $A B C$ Color. Pero se evidencia el fin del régimen puesto que se agudizan las internas en su triángulo de dominación (Partido Colorado, FF. AA., gobierno), se profundiza el desarrollo de los movimientos sociales y acontecen huelgas históricas de la clase trabajadora.

En el campo intelectual, se produce cierta ebullición editorial y surgen varios sellos, como NAPA, Alcándara, El Lector, Don Bosco, Arandurã y RP Ediciones. Todos sacaron colecciones y obras completas (e incluso obras críticas para la ideología oficial) que constituyeron hitos históricos para la industria editorial y la literatura paraguayas.

Para 1989 y durante los primeros años de la transición, la democratización de la cultura se esgrimiría como un proyecto necesario, aunque siempre en el nivel del proyecto, para contribuir a la democratización de la sociedad en su conjunto. Muchos de los artículos de Ticio Escobar, influyente crítico de arte, de esos años se abocan a este dilema entendiéndolo como un llamado a la praxis, es decir, se abocan al tratamiento de herramientas y mecanismos para la instrumentación de políticas culturales acordes al proceso de transición. En este sentido, Escobar sostiene la necesidad de redefinir el "perfil de la comunidad cultural" ya que:

[...] derrocada la dictadura, punto de referencia de prácticas definidas en cuanto opositoras, dicha comunidad quedó desorientada en lo relativo al lugar que debería ocupar durante la transición (1992: 45-46).

Lo central de esa praxis consistiría en des-estronizar la cultura. Distintos autores (Palau et alt., 1989) caracterizan una cultura autoritaria que inficionó la vida cotidiana, para lo cual se habría valido de discursos tradicionales, y que fue administrada, durante la dictadura, por el Partido Colorado. La dictadura habría creado, así, una cultura stronista que penetró en toda la sociedad, incluso en la oposición al régimen, y que constituiría el núcleo duro que deberían desarmar las políticas culturales de la democracia. Para darles entidad a éstas, se establece un marco de enunciación colectivo en torno a una comunidad intelectual o cultural, en la que los mismos autores se inscriben. Esta comunidad cobra relieve, principalmente, por sus funciones a futuro y en estrecha relación con el proceso político iniciado en 1989, que se ofrece como un proceso abierto.

Me interesa resaltar la certeza, que existía en estos discursos, de un fuerte cambio epocal y de un campo intelectual en el tránsito de una reconfiguración vinculada al proceso político. De

\footnotetext{
5 Más allá de que el ideologema del stronismo como "mito paralizador" de la sociedad pueda resultar cuestionable, el régimen efectivamente solidificó prácticas concretas de clientelismo y de una política personalista que calaron en amplios sectores de la sociedad paraguaya.

${ }^{6}$ Roa se había ido de su país en 1947 antes de que se establezca el régimen stronista y, hasta 1982, realizaba viajes breves pero sostenidos al Paraguay.
} 
hecho, la situación se presenta casi como inédita, lo cual tiene que ver también con una seguridad que se pierde, tal como refiere Escobar (1992: 45), la de la "misión heroica" de oponerse a la dictadura. El frente intelectual durante el stronismo había permanecido relativamente cohesionado (incluso en el exilio) en torno a esta necesidad compartida de enfrentar unidos al régimen. Ahora bien, a medida que se asienta el proceso democrático, ese factor de cohesión del campo se pierde y su pérdida se canaliza a través de disputas intelectuales. Es entonces cuando se producen las polémicas con más continuidad y que dividieron, hasta hoy, las aguas del campo intelectual paraguayo.

\section{EL ESCRITOR PARAGUAYO Y LA TRADICIÓN}

Estas polémicas giraron, fundamentalmente, en torno a la figura del escritor paraguayo más reconocido en el exterior, Augusto Roa Bastos, quien estaba emprendiendo su regreso a Paraguay después de varias décadas de exilio. Roa polemiza entonces, aunque con distintos niveles de virulencia, con algunos escritores paraguayos, como Juan Bautista Rivarola Matto, Carlos Villagra Marsal y Guido Rodríguez-Alcalá. Particularmente, la controversia que se produce entre Roa y Villagra Marsal, también escritor pero más conocido dentro del circuito local, en el crucial año de 1989, instauró una lógica que simulaba enfrentar a los exiliados con los que habían permanecido en el país. Esta lógica, sin embargo, reduce la polémica a un aspecto secundario; mientras que un abordaje en profundidad sobre el episodio permite tratar aspectos centrales, tanto de la situación de la literatura paraguaya hasta el momento, como del contexto de democratización que lo contiene. En concreto, el episodio puede ser tratado a partir de tres ejes de análisis: 1) la postulación de una literatura nacional, 2) el exilio como tópico polémico y, además, como factor estructurante del campo literario; y 3) el contexto de la democratización y las tomas de posición que los intelectuales elaboran tras la caída de dictadura.

\section{UNO. LA LITERATURA NACIONAL COMO “LITERATURA AUSENTE”}

En varios ensayos, pero sobre todo en su ponencia ante el III Encuentro Internacional de Escritores en México en $1982^{7}$ y en su famoso artículo, "Una cultura oral" (1991 [1986]), Roa caracteriza a la cultura paraguaya como una cultura predominantemente oral, que tiene la particularidad de ser vehiculizada a través de una lengua otra, indígena y oral, el guaraní. Mientras que la escritura es canal principal de la lengua históricamente dominante, la castellana. Este bilingüismo sostenido en una base jerarárquica resulta en una estructuración diglósica de la cultura, según la cual existe una variedad "culta" y otra considerada "baja". En consecuencia, la inserción de la "cultura oral" en la escritura requiere de la puesta en acción de operaciones de traducción y reducción ${ }^{8}$ de ese trasfondo; operaciones sumamente complejas para el escritor de ficciones que debe articular dos universos disociados por la diglosia: el de la ficción, asociado al guaraní, y el de la escritura, asociado al castellano. Roa define entonces una carencia, la de poder asociar, en la contemplación (Roa Bastos 1982a) del tejido de signos, a estos con la percepción

\footnotetext{
${ }^{7}$ Un extracto de esta ponencia fue publicado en $A B C$ Color el 25 de julio de 1982.

8 Sobre la traducción del guaraní al castellano como reducción, cf. Melià (1997).
} 
auditiva. La postulación de esta carencia lo lleva a caracterizar a la literatura paraguaya como una "literatura ausente":

[...] entendida no como carencia de algunas buenas obras del género narrativo, sino como inexistencia de un corpus de obras cualitativamente ligadas por denominadores comunes; como la falta de un sistema de obras de ficción. [...] todo eso que de una manera abstracta se suele denominar identidad nacional (Roa Bastos 1991 [1986]: 100).

Es decir, la "ausencia" de la literatura paraguaya no se referiría al hecho empíricamente comprobable de que haya o no obras y escritores paraguayos, sino a que éstos no lograron sentar las líneas fundamentales que hacen a una literatura nacional. ${ }^{9}$

En realidad, estas cuestiones obsesionaron durante décadas a Roa Bastos pero en los ochenta, con un campo intelectual en proceso de transformación, algunos escritores reaccionaron desde Paraguay contra lo que creían era una impugnación contra su propio trabajo. Entre ellos, Villagra se erige como vocero. En "Papeles de Última altura", la columna que había empezado a escribir tras el golpe del 89 en el diario Hoy, Villagra Marsal publica "Variaciones sobre narrativa del Paraguay" el 10 de septiembre del 89 y refuta allí "la aseveración, casi acusatoria, de la pobreza - para no decir la ausencia- de la narrativa en el Paraguay. En este país, se asegura, no existe un corpus de literatura de ficción, vale decir que carecemos de un número y una cronología suficientes de textos de ajuste de una tradición" (1991 [1989]: 91-92). Aunque sin citarlas textualmente, Villagra se refiere a las observaciones de Roa Bastos de "Una cultura oral", y que Roa habría repetido en un encuentro organizado por la Cámara del Libro en el mes de septiembre.

Para refutar a Roa, Villagra expone "cuatro argumentos". En primer lugar, toma como sinónimos "corpus" y "tradición”, para luego asentar las líneas fundamentales de esa tradición. Abreva entonces en el famoso argumento borgeano de "El escritor argentino y la tradición" y propone la literatura occidental como acervo también para la literatura paraguaya (Villagra Marsal 1991 [1989]: 92). Lo cual convive -y esto sí es particular del Paraguay- con la tradición de la literatura oral:

[...] subsiste en el Paraguay una acaudalada tradición de oralidad cuentística, guaraní y mestiza, que podría erigirse en formidable sostén de la faena de los jóvenes -y madurosfabuladores en castellano: además, apenas se ha escarmenado hasta ahora esa cambiante, profunda cabellera popular (1991 [1989]: 92-93).

Es decir que, para Villagra, la literatura popular funciona como un acervo del cual puede hacer uso el escritor paraguayo, así como del conjunto de la tradición occidental. La imagen de la "cabellera" apenas escarmenada se refiere a que, según Villagra, la tradición oral ofrece un suelo fértil, abundante y poco aprovechado.

Aquí, en realidad, Villagra parte de su propia experiencia como escritor, ya que su breve obra narrativa ${ }^{10}$ sería un modelo del uso de esa "acaudalada tradición" para la literatura paraguaya

\footnotetext{
9 Para un análisis desde la perspectiva teórica de la "literatura ausente", cf. Benisz (2014).

10 Compuesta solo por dos títulos pero que son clásicos para la literatura paraguaya, "Arribeño del norte" y Mancuello y la perdiz.
} 
en castellano (Benisz 2013). De modo que “acaudalada tradición”, “formidable sostén", junto con otras expresiones como "parcela nutricia", "generosa levadura", "techumbre y tierra firme” (Villagra Marsal 1991 [1989]) son imágenes que refieren a lo oral popular como un sedimento pródigo y plataforma aprovechable para la literatura paraguaya; y además como un territorio susceptible de ser apropiado: acaudalada, parcela, techumbre, remiten a un campo semántico de la tierra como propiedad.

La mediación para que lo popular se transforme en escritura es el trabajo (voluntarista) del escritor. Esto refiere el tercer argumento: "la vocación y el talento auténticos son de naturaleza incoercible [...] pese a todos los pesares, incluido el de la eventual carencia de una tradición narrativa" (Villagra Marsal 1991 [1989]: 93). Finalmente, el cuarto argumento de Villagra es una lista de 39 escritores contemporáneos que demostrarían, con su misma existencia, la de la literatura paraguaya.

Estos argumentos permiten observar que, para Villagra, la mediación -el trabajo escriturario- se sostiene, en la última instancia, en aspectos subjetivos, la vocación y el talento; estos resolverían todas las dificultades que podría acarrear ese pasaje (ese usufructo) de lo oral a la escritura. Claro que Villagra no especifica la naturaleza de ese trabajo como traducción (aunque lo ponga en práctica en su obra) ni considera el conjunto de problemas que pueden significar el pasaje de lo oral a lo escrito y la traducción entre una lengua oral popular y otra "culta". Por el contrario, Villagra reduce esa dimensión de la traducción, puesto que en todo caso ésta puede resolverse con "vocación y talento auténticos". Mucho menos considera las condiciones materiales de los productores de cultura. Aunque sí plantea a la literatura como proyecto futuro y aún pendiente, en tanto habla de un trabajo que "podría erigirse" y "apenas se ha escarmenado".

En cambio, para Roa, la ficción escrita constituye una quimera para el guaraní-parlante que el escritor puede saldar simbólicamente solo a través de una lengua que trabaje sobre un espacio de traducción; es decir, que reponga en la escritura, en formas literarias de tradición occidental y en una lengua continental, símbolos y estructuras con un desarrollo ajeno y paralelo. De acuerdo con la postura de Roa, es esta mediación -que Villagra Marsal considera como algo soluble individualmente- el nodo central de la "ausencia" de la literatura paraguaya.

Esta hipótesis de la "literatura ausente" entra en el artículo mediada por el juicio de Villagra. No aparece la voz de Roa Bastos, ni se menciona o glosa alguno de sus textos, sino que se apela a un conocimiento previo compartido que circula por el campo. De modo que la tesis de Roa es presentada a través de términos que ya suponen una evaluación de Villagra: "aseveración, casi acusatoria, de la pobreza", "denegación", "comentarios", "escamoteo de la narrativa paraguaya". Si Roa habla de ausencia (de la literatura), Villagra habla de denegación (de Roa Bastos), o sea, de un rechazo activo de los "hechos" (los 39 escritores), de modo que Villagra pone el foco en la actitud y el interés del sujeto que niega o acusa, antes que en un posible fenómeno social o cultural.

En resumen, Villagra postula un eje dicotómico que divide posiciones en torno a la existencia o no existencia. La táctica le permite erigirse como defensor de la primera posibilidad, y -en sentido traslaticio- de la misma literatura paraguaya. Su razonamiento parece plantear un campo literario armónico o que naturaliza sin conflicto la superposición de niveles (literatura, 
tradición popular, oralidad, escritura, lengua originaria, cultura colonial). Es decir, Villagra no considera la posible pregnancia de "líneas de fuerza", en términos de Bourdieu, de naturaleza social que contribuyen a hacer de la literatura un campo de lucha y conflicto.

Roa, por su parte, le dedica a Villagra varias respuestas publicadas en el diario Úlitma hora. Uno de los ejes en los que se centra es la confusión de Villagra entre corpus y tradición. Roa explica que el concepto de tradición se refiere a un ente abstracto, de larga data y que corresponde a las líneas culturales que configuran una identidad, por lo cual no es medible a través de la estadística ni puede circunscribirse al "lapso inferior al del curso de una promoción literaria" (Roa Bastos 1989a: 26), como había escrito Villagra. Además, utiliza una serie de términos sensibles para el contexto, vinculados a la dictadura, y los relaciona con Villagra. Por ejemplo, el "autoritarismo" de pretender recrear una tradición con el "censo" (Roa Bastos 1989a: 26), el listado de 39 autores. Por el contrario, para Roa, ni la cantidad de obras ni el corpus bibliográfico implican una tradición. De todos modos, esta diferenciación entre corpus y tradición es explicitada por Roa cuando le responde a Villagra, ya que en "Una cultura oral", ambos conceptos no están claramente delimitados. En ocasión de la polémica, entonces, cita trabajos de Ángel Rama, Antonio Candido y José Carlos Mariátegui (Roa Bastos, 1989b) que le dan mayor espesor conceptual a su formulación pero también sitúan en el marco de la literatura latinoamericana, como una problemática compartida, la tesis de la "literatura ausente".

En esta ocasión, Roa también refuta el postulado borgeano de la tradición occidental, puesto que lo considera preñado de un idealismo sobre el que se asienta una concepción elitista de la literatura. La cultura occidental funcionaría como tradición solo para "una élite instruidísima y cultísima [...], la intelligentsia local” y excluye "a las enormes masas poblacionales sumergidas en la miseria absoluta y en el analfabetismo total" (Roa Bastos 1989c: 30). Claro que Roa antepone aquí la escisión conflictiva entre lo popular y lo letrado por sobre las posibilidades de apropiación o intercambio. En consecuencia, la tradición occidental, como tradición propia o apropiada, puede funcionar solo para una élite. Con ello, Roa responde una aporía con otra, puesto que muchas de las figuras centrales del canon occidental llevan también en su seno el dilema por lo popular. Es decir, los monumentos inaugurales del arte y de la literatura no fueron concebidos en la ideología de la especificidad del arte, sino que fueron incluidos en ella posteriormente y a través de operaciones críticas que, en algunos casos, neutralizaron, cuando lo había, su fundamento popular. Sin embargo, es interesante destacar lo que está detrás de esta afirmación de Roa: la necesidad de que los sectores populares, principales productores de cultura, lo sean también de cultura letrada. Cubrir esa necesidad sería cubrir la "ausencia" de la literatura paraguaya.

De este modo, Roa no podría estar en desacuerdo respecto del otro vértice propuesto por Villagra, el de la oratura popular, puesto que es cimiento también de su propia obra. Pero aquí dirige la cuestión de nuevo hacia el nivel de la irresolución, de la ausencia, en la forma de una pregunta. Roa se pregunta entonces, "cómo se las ingenia el autor de Mancuello para 'escarmenar' esta oralidad cuentística popular" y poder incorporarla a la literatura "con naturalidad y sin violencias" (Roa Bastos 1989c: 30). Esto vuelve sobre los interrogantes respecto de cómo operar ese pasaje de la tradición oral al terreno de lo letrado, pasaje que siempre implica niveles de traducción o de reducción, y que en el contexto de la cultura paraguaya es, además, un 
pasaje entre lenguas de distinta jerarquía social. Desde esta perspectiva, Roa critica la postulación de que la traducción se pueda realizar de forma tan directa y "sin violencias" como subyace al planteo de Villagra.

Por último, la misma lista de escritores que presenta Villagra también es, para Roa, una negación de la literatura como terreno de conflicto. El "censo" es, entonces, un "acopio" acrítico, que no aplica un trabajo de análisis sino que:

[...] omite el más rudimentario esbozo de esas líneas de tensión que están formando nuestra tradición narrativa, puesto que el profesor mete en una misma bolsa textos espléndidos, regulares, malos y hasta mediocres. Levanta luego la bolsa y clama por lo alto con su voz de trueno: "¡Aquí está el corpus...!" (Roa Bastos, 1989d).

\section{DOS. EXILIO: TÓPICO Y MEDIDA}

Como ya mencioné, el disparador de la polémica fue una mesa redonda sobre exilio y dictadura, organizada por la Cámara del Libro en Asunción, en septiembre de 1989, de la que participaron Villagra, Roa y Rubén Bareiro Saguier. Pero además, el exilio reciente, como tópico de los discursos, despliega en la polémica interrogantes éticos y éstos, a su vez, se expresan de acuerdo a la concepción sesentista del compromiso intelectual. Desde este cronotopo del exilio y el compromiso, Roa construye éticamente su lugar de enunciación para contextualizar su regreso y su reinserción al campo intelectual de la post-dictadura, y juzga como oportunista la actitud polémica de Villagra.

En un contexto de campo intelectual permeado por las rencillas políticas, Roa se construye en la soledad de su "soberanía personal" (Roa Bastos 1989a: 27) y esgrime, para realzar el pathos polémico, el no lugar del exilio:

Creo que el exilio me hizo escritor puesto que hice toda mi obra narrativa en los cuarenta años largos de "residencia" en el extranjero. Situación no cómoda ni estimulante para nadie. [...] No me siento un rival para nadie, sino un trabajador de la cultura que desea el progreso de nuestra literatura de ficción y que trabaja con un sentimiento genuino de solidaridad hacia todos los que auténticamente pueden hacerla avanzar por encima y más allá de los clanes y guetos, semejantes a zanjas o "salamancas", a los que nos ha condenado nuestro atraso cultural con su secuela de recelos y rencillas intestinas (Roa Bastos 1989b: 28).

En este sentido, Roa construye el sistema de oposiciones de tal forma que, por un lado, él queda solo en su rebeldía, y por otro, Villagra está respaldado por un contexto que promueve la impostura, la "plaga farisaica" (Roa Bastos 1989a: 27):

Según los íntimos aunque inocultables deseos de éste [Villagra], yo debería seguir estando lo más lejos posible de la tierra natal por mi indisciplinada condición de no querer ser corifeo de nadie y sí un "humilde y modesto" (según sus autocalificaciones más socorridas) elemento de aproximación y colaboración entre los distintos sectores de nuestro mundo cultural. (Roa Bastos 1989d: 26).

Es más: Roa, rebelde solitario, enfrenta el exilio y la violencia de la dictadura al mismo tiempo que enfrenta a Villagra. Según Roa, el oportunismo polémico de Villagra participa de esa violencia, ya que, desde su columna de Hoy, Villagra se dio el "lujo impune de juzgarme sin 
apelación y como en contumacia desde su columna. Como en los tiempos de la dictadura" (1989a: 26).

La postura ética que Roa construye discursivamente, aunque no se condice con su posición central en el campo intelectual, se asemeja a la del prototipo del pamphlétaire de Angenot (1982). Para Angenot, el pamphlétaire enuncia desde la soledad y se ubica al margen del sistema dominante: "Esta palabra excluida, esta voz sin lugar, sin ortodoxia y sin respaldo, es lo que hace del panfleto una forma de literatura" (1982: 74). De modo que no solo confronta con el adversario, sino con el status quo que respaldaría la impostura del discurso opositor. Por ello, Angenot explica la construcción del yo en el género como el de un profeta solitario, una Casandra o un mártir de la ideología, que enuncia una verdad evidente pero negada por el resto de la sociedad.

Paralelamente a esta serie de respuestas, Villagra usa su columna de Hoy como tribuna para responderle, nuevamente, a Roa, durante tres domingos sucesivos. En sus respuestas, Villagra personaliza el debate, prácticamente omite la discusión teórico-literaria y la lleva, por momentos, al terreno de la ética donde él (a diferencia de Roa) habría mantenido la coherencia puesto que “jamás empuerqué mi pluma rindiendo poemas de vasallaje a ningún tirano" (Villagra Marsal 1989a). Aquí, aunque no lo menciona, hay una directa acusación a Roa por el poema "Eternamente hermanos", que había escrito a Juan Perón y Stroessner en 1955 cuando el entonces presidente argentino devolvió al recientemente asumido presidente paraguayo los trofeos de la Guerra contra la Triple Alianza.

Desde este terreno ético, además, Villagra (1989c) cuestiona el carácter del exilio de Roa: quien enuncia desde un espacio de privilegio es el exiliado que habla desde afuera y desde una metrópolis de cierto prestigio (la Universidad de Toulouse) y, por ende, desconoce la actualidad de la literatura paraguaya.

\section{TRES. TOMAS DE POSICIÓN}

Esta polémica entre Roa y Villagra tiene un antecedente en 1982, cuando Juan Bautista Rivarola Matto (1982a y b) salió al cruce de algunas afirmaciones de Roa que (imprecisamente) se habían replicado en la prensa. Sin embargo, en aquella ocasión, Roa no responde a Rivarola y el episodio se cierra con una carta aclaratoria que Roa (1982b) envía al diario Hoy. Ese antecedente resulta significativo al compararlo con la actitud que asume Roa en 1989, cuando recoge el guante y asume la polémica abiertamente. No solo dedica varios artículos a responder a Villagra, sino que, como se pudo ver, el mismo tono de su discurso se carga de la virulencia del polemos.

Este intercambio puede ser leído desde varias aristas: como pase de factura y diatriba personal; dentro del contexto político de la transición que interviene en las tomas de posición intelectual de los escritores; y finalmente, como un análisis de aspectos centrales de la literatura puestos en discusión. Por un lado, como intenté desarrollar, los textos de Roa, efectivamente tienen valor crítico para la literatura paraguaya. Pero, por otro, en sus entregas, Roa descalifica tanto las respuestas de Villagra y sus argumentos, como al mismo Villagra. En este aspecto se observa cómo subyacen los enfrentamientos políticos que el proceso de democratización generaba; al mismo tiempo, es este proceso el que permitió el espacio de apertura y habilitó los 
tópicos de la discusión.

El mismo Roa pone la discusión en relación con los enfrentamientos de la transición; de hecho se pregunta retóricamente por qué Villagra debate "sólo ahora y abruptamente" (Roa Bastos 1989a: 26) algo que él venía sosteniendo hacía años. Para terminar de contextualizar el debate en relación con la transición, se refiere concretamente al encuentro organizado por la Cámara del Libro. Allí, según Roa:

La exaltación de los recuentos de penurias y cicatrices individuales agotó la entera gama de la melcocha sentimentaloide y plañidera de ritual, y adquirió, sobre todo en la intervención de Villagra, tonos patéticos de autocelebración que la volvieron, al menos para mí, a duras penas soportable. [...] Mi rebeldía o renuencia a participar en esa representación bastante histriónica, me valió de golpe la reprobación -la sentí con pavordel tyvyra Carlos por haberle "escamoteado", esta vez, su número (Roa Bastos 1989a: 27).

Por lo general, en sus respuestas, Roa oscila entre el reconocimiento a la vieja amistad que lo había unido a Villagra y juicios severos hacia él. Ya desde el primer artículo sienta posición, sube las dimensiones polémicas, sobre todo para el campo intelectual paraguayo que recién experimentaba las polémicas inaugurales de su proceso de reconfiguración. Entre los juicios que Roa dispara contra Villagra, lo trata de ególatra, considera que es "capciosa" su "acusación", lo llama su "no buscado ni deseado discípulo", "una persona torva, irascible, desleal, por el hecho de llenar una columna"; al mismo tiempo, afirma que no lo culpa a él sino a sus "corifeos instigadores" y que, por ende, no le responde solo a Villagra (Roa Bastos 1989a). Aquí se observa lo oscilante del discurso de Roa, como si sentara una actitud beligerante hacia Villagra pero, a la vez, quisiera despersonalizar el debate y ubicar a Villagra como representante de la posición hegemónica dentro del campo, ante la cual Roa (de nuevo, individualiza) se considera un rebelde.

El recurso ad hominem no desvirtúa necesariamente los argumentos de la polémica y, además, puede influir eficazmente, para los fines de la posición que lo enuncia, en la determinación del público. Amossy (2003) entiende que si, desde una perspectiva lógica, el argumento ad hominem es una falacia, es, en cambio, completamente válido desde una perspectiva interaccional; puesto que si la eficacia del discurso tiene que ver también con rituales sociales que legitiman la palabra, entonces "el argumento ad hominem puede llevarse oportunamente sobre la posición social y la legitimidad institucional del orador: puede poner en duda su derecho y su capacidad de presentar un discurso argumentativo determinado" (Amossy 2003: 415). De este modo, Villagra está muy presente en el discurso de Roa o, mejor dicho, la imagen que Roa hace de Villagra domina grandes pasajes de sus artículos. Roa hace un uso recurrente de la cita e inserta repetidamente la voz de su oponente a través de citas textuales, a las que inmediatamente matiza con su evaluación, o singulariza irónicamente términos de Villagra como "escarmenar", "escamotear", "acaudalada". Por otro lado, Roa combina aspectos personales con características sociales del sujeto a través de un encadenamiento de imágenes y juegos de palabras: Villagra a veces es Mancuello, protagonista de Mancuello y la perdir, otras una perdiz de vuelo al ras o el "halconero de Alcándara" (su editorial) volador de últimas alturas (Roa Bastos 1989d). Las figuras destacan, en la argumentación de Roa, distintas características con las que recubre a su adversario: la altanería del "etnocentrismo cimarrón", el oportunismo, la perspectiva panorámica y simplificadora desde las alturas de la clase propietaria (Roa Bastos 1989a). 
En la descalificación conjunta del adversario y de la tesis que éste postula, Roa Bastos conjuga su gesto polémico. En su primer artículo, es especialmente fuerte la descalificación personal, lógica que Roa abandonaría transitoriamente en el segundo. Él juzga severamente el personalismo de Villagra quien interpreta los argumentos de Roa como exclusivas afrentas hacia su persona. Roa considera que el pathos "dostovievskiano" del discurso de Villagra está asociado a un ethos de clase, por lo cual la impugnación al personalismo de Villagra le permite avanzar en su propia argumentación: “¿qué código de valores o disvalores maneja Villagra en el planteamiento de estos problemas que nada tienen que ver con los cólicos morales de una conciencia compungida, y sí, mucho con la conciencia objetiva de nuestra realidad socio-cultural?” (Roa Bastos 1989a: 26). Roa quiere dar a entender que la confusión de Villagra que mezcla cuestiones personales con aspectos socio-culturales, esconde una postura ideológica de adecuación y defensa del status quo o de ocultamiento interesado de las estructuras de dominación que generan esas condiciones.

El último artículo de Roa conecta varios de los argumentos que esgrime contra Villagra con aspectos más generales del proceso de democratización. Prácticamente esboza un programa para la cultura: crear un "Foro Cultural Interpartidario", llevando la línea de la reconciliación política al plano cultural. Esto demuestra su interés en participar activamente de las políticas de la transición para abordar, justamente, los problemas estructurales de la cultura paraguaya que hacen a la ausencia de su literatura:

Esos problemas están ahí y tienen que ser estudiados con verdadera conciencia autocrítica, no con "pucheros" lacrimógenos de un supuesto "honor nacional" vejado y vilipendiado. Son causas de carácter histórico, social, económico y cultural las que, a partir de la destrucción del país en 1870, han provocado otras carencias -más importantes aún que el atraso de la literatura narrativa- como, por ejemplo, la inestabilidad de las instituciones fundamentales de la República, la inexistencia de un verdadero Estado de Derecho (Roa Bastos, 1989e).

Finalmente y como modo de zanjar la polémica, Roa propone un tribunal que "arbitre" entre su posición y la de Villagra, compuesto por Evelio Fernández Arévalos, Josefina Plá y Ramiro Domínguez, como "vía de conciliación y arreglo que pueda contribuir al reencuentro y concertación de los sectores de nuestra cultura, fragmentada por la acción disolvente de la larga dictadura" (Roa Bastos 1989b: 29). "Conciliación”, “reencuentro" y "concertación” están en la misma sintonía que las propuestas políticas de Roa en el contexto de la post-dictadura, cuando se vincula al Encuentro Nacional (P-EN), un nuevo partido que abjuraba de los tradicionales; pero son llamativos en relación con la impugnación al campo intelectual que realiza en la polémica. De alguna forma, esta resolución por tribunal plantea una especie de resolución ex machina y una "institucionalización" por vía "jurídica” de la violencia que supone la polémica: un tribunal que reinstaure externamente el logos por sobre el pathos con que los polemistas desbordan sus discursos, con la sentencia de un tercero.

Se trataría, en consecuencia, de una anulación de la polémica como tal, es decir, como género que se constituye en la dicotomización de las posiciones del campo y que no permite el cierre de una posición "victoriosa", sino que depende, en todo caso, de su capacidad de influir sobre el público, algo no medible con instrumentos o instancias puramente lógicos (Benisz s/f). 
Si en los artículos de Roa se podía observar una ambivalencia entre el reconocimiento a la amistad de Villagra y los ataques ad hominem hacia él, al mismo tiempo que la reflexión teórica sobre la literatura paraguaya; en cambio, en los artículos de Villagra se destaca un fuerte tono de defensa. Entiende la discusión como una afrenta personal que lo convierte en "víctima", lugar del cual pretende rescatarse con una prosa rimbombante que se mueve a través de sobresaltos, por momentos cae en el deshonor de la dignidad pisoteada y luego arremete con violencia. Este énfasis en aspectos subjetivos, incluso irracionales, le permite esquivar los argumentos teóricocríticos de Roa, sobre los que casi no discute, sino que resalta -y responde en el mismo sentidolas descalificaciones del orden de lo personal. En este sentido, Villagra no solo considera que hay motivos (subjetivos) escondidos en la "sobre-reacción" (1989a) de Roa, sino que para él esto es lo central del debate.

En cuanto al aspecto propiamente literario de la disputa, para deslegitimar la postura de Roa, esgrime como argumento una afirmación que el mismo Roa Bastos había proferido: según Villagra, Roa habría reconocido no saber qué se producía por entonces en Paraguay, por ende no tendría elementos para plantear la "inexistencia" de la literatura paraguaya (Villagra Marsal 1989b). Aunque también reconoce que existe un "pozo cultural" pero que se trata de una cuestión "geopolítica" porque los escritores paraguayos "no han logrado aún subir a los circuitos internacionales de edición y distribución lo cual, desde luego, no es sólo un problema narrativo sino genéricamente cultural y geopolítico" (1989b). Pareciera enfatizar, en esta asociación entre lo "cultural" y lo "geopolítico", elementos externos (falta de difusión, mercados, etc.) antes que problemáticas estructurales de la sociedad paraguaya, como refiere Roa. Si el "pozo cultural" ensombrece el trabajo de los escritores paraguayos del llamado exilio interior, en cambio:

[...] a Roa Bastos ni le rozan estas cuestiones, obviamente porque no las vive en carne propia, y merced a ello puede dedicarse a transponer, desairar, disminuir o escamotear (sí, señor, me ratifico en ese dicho), con gustosa liviandad, la narrativa de su país (Villagra Marsal 1989b).

"Pero tampoco me presto a ser el payaso de las bofetadas", continúa Villagra (1989b), y enfrenta las "bofetadas" ad hominem de Roa con la exaltación de un pathos sobrecargado de violencia viril que, por momentos, roza la hipérbole. Resignifica, en este sentido, las interpelaciones que le realiza Roa. Si éste destaca la pertenencia social de Villagra como miembro de una familia tradicional, por su parte, Villagra elide mencionar los condicionamientos sociales para centrarse en condiciones subjetivas y pretendidamente universales, como la "dignidad".

A esta construcción le agrega, en su última columna sobre el tema, el binomio democraciadictadura:

[...] justamente en estas semanas en que la sociedad paraguaya exhibe indicios de una terminante recusación a las viejas y nuevas impunidades del stronismo, tampoco yo, desde mi humilde pero enhiesta dignidad personal, estoy dispuesto a soportar que un señor, por más encumbrado que sea o que a él así le parezca, retorne a disfrazar de réplica literaria sus enconos a sol abierto y sus resentimientos de medianoche (Villagra Marsal, 1989c).

Nuevamente, los artículos empalman con el contexto de democratización. Villagra compara su reivindicación personal con la pugna entre "tradicionalistas" y "democráticos" que -en esos 
días- se daba en el seno del Partido Colorado pero que también atravesaba a la sociedad paraguaya en su conjunto. Se compara con las tendencias democratizadoras que empezaban a dominar el escenario político y social y revierte, en consecuencia, el lugar en que lo había situado Roa cuando comparó su "juicio sin apelación” con las prácticas de la dictadura.

La condena a la dictadura stronista es contundente y compartida por el campo intelectual, pero además su experiencia reciente se erige como unidad de medida o parangón para los debates de la democratización, de modo que lo condenable, tanto para Villagra como para Roa, se vincula con el autoritarismo reciente, mientras la democracia es un valor indiscutido para distintas esferas políticas e intelectuales, sociales e individuales. El hecho de vincular al adversario con aspectos de la dictadura y, al mismo tiempo, asumir la democratización como un problema también de los escritores, demuestra no solo la injerencia del contexto político y social en los debates literarios, sino además el modo en que éste determina una escala de valores que se aplica también en el campo intelectual y que se usa polémicamente para delimitar las líneas de fuerza. Es decir, las líneas de fuerza que hacen a la polémica también la exceden, por eso es inviable que esta tensión sea artificialmente regulable por un tribunal ad hoc en un intento de anular el conflicto.

Sin embargo, fue la estrategia de Villagra (la de personalizar el conflicto) la que resultó eficaz, ya que el énfasis en lo personal y no en lo literario marcó la forma en que fue leída la polémica por gran parte del campo intelectual asunceno y por la crítica que ha trabajado el episodio. En consecuencia, se instalaron los bandos "pro-Roa" y "anti-Roa" (los términos son de Langa Pizarro 2001: 178), los escritores paraguayos se abroquelaron en torno a alguno de los dos sectores y los "anti-Roa" aprovecharon ese quiebre para, entonces sí, abrir el campo de discusión a cuestionamientos éticos o políticos. ${ }^{11}$ Según Peiró Barco:

[...] la dureza y el ataque personal a Carlos Villagra Marsal sorprendió [sic] a todo el mundo, incluso porque en el fondo estaban algo de acuerdo cuando ambos se referían a las circunstancias históricas que impidieron el florecimiento de la narrativa. Algunos rumores afirman que en el fondo había circunstancias de pugna por un lugar destacado en el ámbito cultural de la política, teniendo en cuenta que Villagra era liberal y Roa Bastos simpatizaba en cierta medida con una fuerza que luego sería Encuentro Nacional, la que surge de los descontentos de los partidos tradicionales paraguayos (2002: 146).

Los mismos críticos que han abordado el episodio, no vieron en la tesis de la "literatura ausente" el planteo de una problemática vinculada al bilingüismo y la escritura, sino la egotista intención de Roa de negar lo que se producía en su país para reivindicarse como el único escritor paraguayo. Peiró Barco, por ejemplo, asume esta lectura al punto que su interpretación parece una continuación, una línea de diálogo más, de la polémica, reducida ésta al acto de mala fe de un escritor consagrado. Si "la figura de Carlos Villagra Marsal llegó a salir fortalecida por la defensa que hizo" de los escritores paraguayos, en cambio, Roa Bastos: "Silencia los nombres de los autores en el contexto internacional, posiblemente para acrecentar su propio prestigio" (2002: 149).

${ }^{11}$ Como lo hizo Guido Rodríguez-Alcalá. Al respecto, Benisz (2017). 


\section{CONCLUSIONES}

El hecho de que se hayan privilegiado las interpretaciones de índole subjetiva en torno a la polémica y que la discusión literaria haya pasado a una instancia secundaria, demuestra ciertas limitaciones del campo intelectual, en proceso de democratización, para dar cuenta de sus debates internos.

Estas limitaciones obturan el hecho de que, más allá del ajuste de cuentas personal, Roa realiza propuestas críticas ciertamente novedosas en el campo intelectual paraguayo, como la de considerar la relación entre oralidad y escritura como factor de conflicto y, con ello, ponderar el contenido popular de la literatura vehiculizado en la lengua. Propuestas que profundiza ante la necesidad de argumentar que le significa la polémica. En este sentido, el episodio permite, así sea parcialmente, una verdadera "apología de la polémica"; puesto que ésta, como género, se descalza de su destino de género de la ideología y deviene territorio susceptible de pensamiento crítico.

En cuanto a las tomas de posición que los intelectuales elaboran tras la caída de la dictadura, la polémica Villagra-Roa muestra dos tipos de posicionamiento. Por un lado, la reivindicación del Partido Liberal y de los paradigmas políticos anti-autoritarios, tras décadas de coloradismo, en el caso de Villagra. Por otro, la apuesta de Roa por nuevos espacios políticos descontentos con los partidos tradicionales. Sin embargo, más allá de estas posiciones, el consenso quedó sellado en torno a la condena de la dictadura y a la democracia como valor indiscutible. La postulación de ese consenso no obtura -sino que se constituye en- el dinamismo expresado en el aumento del caudal polémico. Por eso, la ruptura del frente intelectual resulta un síntoma del proceso de reestructuración del campo y del escenario novedoso que se abría con el regreso de los exiliados, el aumento de publicaciones y la democratización de los espacios de la cultura, antes que un obstáculo a ese proceso.

Esto último nos permite considerar el exilio, que actúa como tópico tanto como factor estructurante, al punto que dividió las interpretaciones posibles en torno a lo literario de acuerdo con el espacio de enunciación que material y subjetivamente construyeron los polemistas.

Pero además, la literatura ausente es, finalmente, una literatura exiliada. Puesto que, al mismo tiempo que el exilio constriñó las posibilidades materiales para el desarrollo de la literatura paraguaya, esa "limitación" también implicó - e implica- la complejidad de una cartografía migrante. En este sentido, el problema sería no tanto la "existencia" o no de una literatura para el Paraguay, sino el carácter "nacional”, como proyecto moderno y letrado, de esa literatura. 


\section{BIBLIOGRAFÍA}

Amossy, Ruth (2014). Apologie de la polémique. Paris: Presses Universitaires de France.

Amossy, Ruth (2003). "L'argument ad hominem dans l'échange polémique". Declercq, Gilles et al. (eds.). La parole polémique. Paris: Honoré Champion Éditeur: 409-423.

Angenot, Marc (1982). La parole pamphlétaire. Contribution à la typologie des discours modernes. Paris: Payot.

ARDiTI, Benjamín. "Adiós a Stroessner: Nuevos espacios, viejos problemas". Nueva sociedad 102 (1989): 24-32.

BENISZ, Carla. "Literatura paraguaya, transculturación y polémica: las formas de una 'literatura ausente". Revista chilena de literatura 87 (2014): 23-46.

BENISZ, Carla. "Las polémicas inaugurales de la transición a la democracia. Los casos argentino y paraguayo". Literatura: teoría, historia y crítica, 19.1. (2017).

BENISZ, Carla (2013). "Polémica, transculturación y las reescrituras de Mancuello y la perdiz". VI Taller "Paraguay desde las Ciencias Sociales". Grupo de Estudios Sociales sobre el Paraguay-Facultad de Ciencias Sociales-UBA, Buenos Aires, 27, 28 y 29 de junio de 2012.

BENISZ, Carla (s/f). La "literatura ausente". Augusto Roa Bastos y las polémicas del Paraguay post-stronista. Buenos Aires: Editorial sb. (En prensa).

Bourdieu, Pierre. (2002 [1966]). "Campo intelectual y proyecto creador". Campo de poder, campo intelectual. Itinerario de un concepto. Buenos Aires: Montressor: 9-50.

CREWE, Jonathan. (2004). "Can Polemic be Ethical? A response to Michel Foucault". Gallop, Jane (ed.). Polemic. Critical or uncritical. New York- London: Routledge: 135-152.

Croce, Marcela (comp.). (2006). Polémicas intelectuales en América Latina: del meridiano intelectual al caso Padilla. Buenos Aires: Simurg.

Croce, Marcela (comp.). (2007). La discusión como una de las bellas artes. De la revolución literaria a la literatura de la revolución. Buenos Aires: Simurg.

DE DIEGO, José Luis (2000). Campo intelectual y campo literario en la Argentina (1970-1986). (Tesis doctoral). La Plata: Facultad de Humanidades y Ciencias de la Educación-UNLP.

Escobar, T. (1992). Textos varios sobre cultura, transición y modernidad. Asunción: Agencia Española de Cooperación Internacional-Centro Cultural Español Juan de Salazar.

Langa PiZarro, Mar (2001). Guido Rodriguez-Alcalá en el contexto de la narrativa histórica paraguaya. (Tesis doctoral). Alicante: Universidad de Alicante-Biblioteca Virtual Miguel de Cervantes.

Melià, Bartomeú (1997). El guarani conquistado y reducido. Ensayos de etno-historia. Asunción: CEADUC-CEPAG.

Murat, Michel (2003). "Polémique et littérature". Declerq, Gilles et al. La parole polémique. Paris: Honoré Champion Éditeur : 11-15. 
PALAU, Tomás et al. (1989). "Cultura cotidiana, autoritarismo y campos culturales. Formación y tranformaciones recientes en el Paraguay”. AA.VV. ¿Hacia un nuevo orden estatal en América Latina? Innovación cultural y actores socio-culturales. Buenos Aires: CLACSO: 291-357.

PEIRÓ BARCO, José (2002). Literatura y sociedad. La narrativa paraguaya actual (1980-1995) (Tesis doctoral). Alicante: Biblioteca Virtual Miguel de Cervantes.

RABINOW, Paul (1984). "Polemics, politics and problematizations". Rabinow, Paul (ed.). The Foucault Reader. New York: Pantheon Books: 381-390.

RICHARD, Nelly (2007). Fracturas de la memoria. Arte y pensamiento crítico. Buenos Aires: Siglo XXI.

Rivarola Matto, Juan Bautista (26 de marzo de 1982a). "Historia y literatura en Paraguay". Hoy: 8-9.

Rivarola Matto, Juan Bautista (31 de marzo de 1982b). "La literatura paraguaya existe". Hoy: $8-9$.

RoA Bastos, Augusto (25 de julio de 1982a). "De narradores y folletineros". Abc Color/ Suplemento cultural: 3.

ROA Bastos, Augusto (12 de abril de 1982b). "Roa Bastos dice que le tergiversaron". Hoy: 8.

ROA BASTOS, Augusto (1991 [1986]). "Una cultura oral". Antología narrativa y poética. Documentación y estudios. Barcelona: Anthropos: 99-111.

RoA BASTOS, Augusto (16 de octubre de 1989a). "Una réplica o confesión desde un largo exilio". Última hora: 26-27.

RoA Bastos, Augusto (17 de Octubre de 1989b). Augusto Roa Bastos: "Que hablen los que saben". Última hora: 28-29.

ROA BASTOS, Augusto (24 de Octubre de 1989c). "Los argumentos de Villagra”. Última hora: 30.

ROA BASTOS, Augusto (25 de Octubre de 1989d). "Una galaxia con agujeros negros". Última hora: 26-27.

RoA Bastos, Augusto (26 de Octubre de 1989e). "El análisis que todos necesitamos". Última hora: 30 .

Villagra Marsal, Carlos (1991 [1989]). "Variaciones sobre narrativa del Paraguay". Papeles de Última altura. Asunción: Editorial Don Bosco: 91-95.

Villagra Marsal, Carlos (22 de Octubre de 1989a). "La única, obligada respuesta (I)”. Hoy: 15.

Villagra Marsal, Carlos (29 de Octubre de 1989b). "La obligada respuesta”. Hoy: 15.

Villagra Marsal, Carlos (5 de Novimiembre de 1989c). "La obligada respuesta (III, final)". Hoy: 15 